\title{
Association of trait and specific hopes: cross sectional study on students and workers of health professions in Split, Croatia
}

Mario Malički, Domagoj Marković, Matko - Marušić

Introduction: Hope (hoping) is most commonly assessed as a dispositional trait and associated with quality of life, self-care agency and non-attempts of suicide. However, little research has been conducted on hoping for specific events. Materials and Methods: We distributed a survey consisting of Integrative Hope Scale (HIS) and visual analogue scales on which respondents could declare their levels (intensity) of hope for specific events, to all first year health students enrolled at the University Department of Health Studies, Split, Croatia in 2011/12, as well as to working health professionals attending a nursing conference in April 2012.Results: A total of 161 (89.4\%) students and 88 (89.8\%) working health professionals returned the completed questionnaires. We found high trait hope scores of students and working health professionals ( $\mathrm{Md}=111,95 \% \mathrm{Cl} 109-113$ vs. $\mathrm{Md}=115,95 \% \mathrm{Cl} 112-119 ; \mathrm{U}=5353, \mathrm{P}=0.065)$, and weak to moderate correlations of trait and specific hopes ( $r=0.18$ to 0.48 , Spearman's rank correlation coefficient). Students and workers reported 31 different things they hoped for most in life, of which the most prevalent were being healthy and happy. There was very little agreement between participants' reported influence of the four factors compromising the trait hope (selfconfidence, ambition, optimism, and social support) on their specific hopes. Conclusions: Our findings, while strengthening the validity of hope as a trait, indicate that specific hopes of individuals are moderated by factors not captured by the IHS trait scale. Further research should explore specific hoping in detail, as well as the effectiveness of interventions aimed at increasing specific or generalized hoping. 
1 Association of trait and specific hopes: cross sectional study on students and

Mario Malički, Domagoj Marković, Matko Marušić

Department of Research in Biomedicine and Health, University of Split, School of Medicine, Split, Croatia

Address: $\quad$ University of Split, School of Medicine

Šltanska 2, 21000 Split

10

Croatia

e-mails: $\quad$ Mario Malički - mario.malicki@mefst.hr

Domagoj Marković - markovic.domagoj@gmail.com

Matko Marušić - matko.marusic@mefst.hr

14

Corresponding author:

Mario Malički, MD, MA

Department of Research in Biomedicine and Health

19 University of Split School of Medicine

20 Šoltanska 2

2121000 Split, Croatia

22 Phone/Fax: +385 21557820

23 e-mail: mario.malicki@mefst.hr 


\section{Abstract}

25 Introduction: Hope (hoping) is most commonly assessed as a dispositional trait and associated with quality of life, self-care agency and non-attempts of suicide. However, little research has been conducted on hoping for specific events.

Materials and Methods: We distributed a survey consisting of Integrative Hope Scale (IHS) and visual analogue scales on which respondents could declare their levels (intensity) of hope for specific events, to all first year health students enrolled at the University Department of Health Studies, Split, Croatia in 2011/12, as well as to working health professionals attending a nursing conference in April 2012.

Results: A total of $161(89.4 \%)$ students and $88(89.8 \%)$ working health professionals returned the completed questionnaires. We found high trait hope scores of students and working health professionals $(\mathrm{Md}=111,95 \% \mathrm{CI} 109-113$ vs. $\mathrm{Md}=115,95 \% \mathrm{CI} 112-119 ; \mathrm{U}=5353, P=0.065)$, and weak to moderate correlations of trait and specific hopes ( $\mathrm{r}=0.18$ to 0.48 , Spearman's rank correlation coefficient). Students and workers reported 31 different things they hoped for most in life, of which the most prevalent were being healthy and happy. There was very little agreement between participants' reported influence of the four factors compromising the trait hope (selfconfidence, ambition, optimism, and social support) on their specific hopes.

41 Conclusions: Our findings, while strengthening the validity of hope as a trait, indicate that specific hopes of individuals are moderated by factors not captured by the IHS trait scale. Further research should explore specific hoping in detail, as well as the effectiveness of interventions

44 aimed at increasing specific or generalized hoping. 
45

46

47

48

49

50

51

52

53

54

55

56

57

58

59

60

61

62

63

64

65

66

67

\section{Introduction}

Hope (hoping) is regarded as the earliest and the most indispensable virtue inherent in the state of being alive (Erikson 1964). It is the central tenet of religions, especially Christianity (Benedict XVI 2006; Titus 1:2 2011), and an indispensable companion of illness and healing. It accompanies researchers during their scientific discoveries and individuals during their tribulations. Hope has been a popular topic in literature and arts, ever since its entrapment in Pandora's box (White 1914); and recently, it has become the topic of growing research in the fields of positive psychology, philosophy, nursing and medicine (Cutcliffe \& Herth 2002; Kylma \& Vehvilainen-Julkunen 1997; Schrank et al. 2008; Smith 2012; Snyder et al. 1996). Hope has been positively correlated with quality of life (Evangelista et al. 2003), self-care agency (Alberto \& Joyner 2008), caregiver burden (Zink Jadaa 2008), and non-attempts of suicide (Meadows et al. 2005). However, its measurement and conceptualization is still a topic of great debate (Boyd 2015; Bright et al. 2011; Kylma \& Vehvilainen-Julkunen 1997; Lopez \& Snyder 2003; Schrank et al. 2008). In short, although hope is widely perceived as something that can be higher for one object or event than for another and that can fluctuate in its intensity, thresholds and norms for specific hopes in populations, or patients affected or recovering from serious illnesses, have not been explored or measured. Researchers have instead focused on qualitatively identifying factors that generate or quell hope (Soundy et al. 2014), or have focused on quantitatively measuring hope, either as an universal (trait) that applies across situations and times; or more specifically as state hope, a person's current hoping disposition (Lopez \& Snyder 2003; Snyder et al. 1996). More than 32 instruments for the measurement of hope have been developed, and recently researchers have combined the properties of the most commonly used instruments (Miller Hope Scale, Herth Hope Index, Snyder Hope Scale) into an Integrative Hope Scale (IHS) (Schrank et 
68 al. 2011). It was the goal of our research to determine the association of the universal (trait) 69 hope, measured by the IHS, with hoping for specific events, measured by declaring the intensity

70 (level) of hope on visual analogue scales. Additionally, to further determine the relationship

71 between the universal and specific hoping, we explored the congruency between the strongest

72 scoring factor of the IHS trait scale (confidence, positive future orientation, lack of perspective,

73 social relations) and the participants' perception regarding which factor influenced their specific

74 hoping the most. 


\section{Materials and Methods}

76

77 78

\section{Questionnaire}

The English version of the IHS had been translated into Croatian by the authors and then back translated by an independent language expert to confirm its validity. Four items were reformulated in the process. Alongside demographical questions on age and sex, we also asked the participants to declare the level (intensity) of their specific hopes on the visual analog scale (VAS), graded from 0 to 100 (with every 10 intervals marked), for two different events: finishing their studies in time and being healthy at the age of 60 . We then asked the respondents to name (using an open ended question) what they hope for most in life, and to designate their level of hope for that stated goal. Following each of the VAS questions we also asked the respondents to list the four factors: self-confidence, ambition, optimism, and social support; from most to least contributing to their previously stated level of hope (Appendix 1). We chose these four factors as they compromised the IHS subscales (factors): 'trust and confidence', 'positive future orientation', 'lack of perspective', 'social relations and personal value'(Schrank et al. 2011). As the stated goals were positive, we found that 'optimism' as a term best captures the inverse of the 'lack of perspective' subscale.

\section{Sampling and procedures}

We used two-stage convenience sampling of two different age groups of health professionals. First, in order to assess if the level of hope declared on the VAS or IHS could be influenced by the order by which examinees filled out these questionnaires, we randomized all first year students of health studies at the University of Split (who enrolled in their first year of studies in 2011/2012) into two groups: the $1^{\text {st }}$ group was given the IHS questionnaire followed by the VAS, while the $2^{\text {nd }}$ group was first given the VAS followed by the IHS. A simple random number 
98 generator was used for random allocation to the groups. As we found no evidence that the order

99 of presenting questionnaires influenced either IHS or VAS scores (Supplementary Table 1), in

100 further analysis we treated both groups as one. Additionally as the student population was age-

101 homogeneous, in order to check for the possible influence of age on IHS or VAS scores, we

102 administered the questionnaire to the working health professionals who attended the Education

103 for lecturers of nursing courses in April 2012, Split. All of the working health professionals were

104 given a questionnaire in which the IHS questionnaire was printed first. Cronbach's alpha of the

105 IHS for both groups combined was 0.869 (95\% CI=0.843-0.892) showing good internal

106 consistency.

107 Statistical analysis

108 Frequencies and percentages were used for the description of categorical variables, and median

109 (Md) and interquartile range (IQR) for non-normal distributions. The Mann-Whitney U test was

110 used to assess the difference in medians between the groups, while the chi-square test was used

111 to compare frequency distributions of categorical variables. Correlations between the CIHS total

112 and subscale scores with VAS scores were assessed by Spearman's rank correlation coefficient.

113 Concordance of the ranking order with which the participants graded factors which influenced

114 their hope levels were determined using Kendall's coefficient. The level of significance for all

115 statistical tests was 0.05. Data was analyzed with SPSS statistical package 19.0 (SPSS; Chicago,

116 Illinois, USA).

\section{Ethical approval}

118 The study was approved by the ethical review board of University of Split, Croatia (no. 003-

119 08/11-03/0005). 


\section{Results}

121 Demographic data

122 A total of $161(89.4 \%)$ students of first year health studies (132 women, 26 men, missing data for

1233 respondents) participated in the study, as well as $88(89.8 \%)$ working health professionals

124 attending a nursing conference ( 86 women, 2 men). The students were 18-47 years old, with a

125 median age of $19(\mathrm{IQR}=19-21)$, and the workers were 22-70 years old, with a median age of 48

$126(\mathrm{IQR}=38-52)$.

\section{Comparison of students and working health professionals}

128 There was no significant difference between the two groups in their IHS total score (Md=111, $12995 \%$ CI 109-113 vs. $\mathrm{Md}=115,95 \%$ CI 112-119; $\mathrm{U}=5353, \mathrm{P}=0.065)$. However, workers had 130 higher scores on the IHS' 'trust and confidence' and 'social relations and personal value' 131 subscale scores, as well as higher hopes (designated on VAS) of being healthy at the age of 60 132 and for the things they most hoped for in life (Table 1).

133 Sex differences were observed for the student population, with males reporting higher hopes for

134 being healthy at the age of $60(U=1153.5, p=0.009)$.

135 For both groups, universal (trait) hope, measured by the IHS, showed a significant strength of 136 correlation ( $\mathrm{r}=0.18$ to 0.48 ) with specific hopes, measured by the VAS (Table 2 ).

137 When answering an open ended question on what their most hoped-for thing in life was, students 138 and workers listed 1 to 5 answers, with no differences between the groups on the number of 139 answers they listed $(\mathrm{Md}=1,95 \%$ CI 1-2 vs. $\mathrm{Md}=2,95 \%$ CI 1-2, $\mathrm{U}=5373, \mathrm{P}=0.169)$.

140 Cumulatively, 31 most hoped-for concepts emerged, with health and happiness being the most 141 prevalent in both groups. However, the frequency distribution of individual concepts showed 
142 several significant differences, with students hoping more for health, work and family, while

143 workers hoped more for life contentment (Table 3).

144 Influence of hope trait factors on specific hoping

145 After designating levels of hope on the VAS scales participants declared how much the 4 factors

146 (self-confidence, ambition, optimism, and social support) contributed to the levels of hope they

147 designated. The same order of the factors was listed by $23(14.3 \%)$ students, and $0(0 \%)$ workers.

148 The order of the factors between different participants showed very little agreement, even when

149 participants with highest or lower trait hope scores were analyzed separately (Kendall's W from

$150 \quad 0.024$ to 0.117 ; Supplementary Table 2).

151 Of the four factors, optimism was most commonly chosen by the participants of both groups as

152 the factor which contributed most to the hope of being healthy at the age of 60 , as well as for

153 their most hoped-for thing in life $\left(\chi^{2}=2.632, \mathrm{P}=0.004\right.$ and $\chi^{2}=6.438, \mathrm{P}=0.09$, respectively). No

154 single factor was chosen by the students as that which contributes most to their hope of finishing 155 studies in time, but rather all 4 factors (self-confidence, ambition, optimism, and social support)

156 were represented in equal measure $\left(\chi^{2}=6.903, \mathrm{P}=0.075\right.$, Supplementary Table 3$)$.

157 In order to see if the factor which individuals chose as the most influential to their specific hopes

158 was also the one with the highest score on the IHS (sub)scale, we ranked the IHS subscales 159 scores of each individual from highest to the lowest. This resulted in ambition (positive future 160 orientation) being expressed as the strongest factor of the four for both groups of participants 161 (Supplementary Tables 2 and 3). 


\section{Discussion}

163 Our study showed that there were no differences between total scores of universal (trait) hope,

164 measured by an Integrative Hope Scale, between training and working health professionals; and

165 that the trait hope was weakly to moderately correlated with the intensity (level) of hope for

166 specific events, declared on visual analogue scales. These findings strengthen the validity of

167 hope as a human trait, and imply its stability through time, as also indicated by Schrank et al. on

168 the general population of Austria (Schrank et al. 2011). The IHS scores in our sample were

169 however higher than those found in Austria suggesting either cultural or quality of life

170 differences, or even the specifics of the caring profession which our sample was based on.

171 Averill et al. have shown that religion, specifically Judeo-Christian influences on the Western

172 nations, compared to Confucianism influences on the Eastern nations, left a profound influence

173 on both the conceptual grasping and importance of hope (Averill et al. 1990). Although there is a

174 higher percentage of declared Catholic population (86.28\%) in Croatia than in Austria (73.66\%)

175 (Croatian bureau of statistics 2013; Statistics Austria 2001), neither the Schrank et al. study

176 (Schrank et al. 2011) nor our study, checked for religious orientation, requiring that these

177 differences be explored in further studies.

178 Higher levels of the subscales 'trust and confidence' and 'social relations and personal value' of

179 working health professionals in our study compared to those of the student population, most

180 likely result from age specific developmental characteristics and family status. Similarly, the

181 differences observed in the most hoped-for things in life for these two populations could

182 originate from the higher number of individuals within the working population who have already

183 achieved their hopes and goals for work and family, and are therefore more oriented toward life

184 contentment and spiritual fulfillment. Workers' higher levels of hope for being healthy at the age 
185 of sixty could result from the facts that our sample consisted only of an active working 186 population and that the workers were also closer to the 60 year-mark, meaning that they could,

187 based on their age and health so far, better evaluate their future health. Our findings of male 188 students having higher hopes for being healthy at the age of 60 could originate from observed 189 gender differences in the perception of health (Suris et al. 1997), yet, as our sample included 190 only a small number of male students $(n=26)$ this difference needs to be confirmed in further 191 studies.

192 Our study also adds further support for hope being an emotion that can be expressed and 193 recollected (Smith 2012), as the most hoped for things in life our participants listed are almost 194 identical to those in the Averill's study of analysis of hope (Averill et al. 1990), in which, 195 wanting to "eliminate" abstract hopes, researchers asked participants to name events in the 196 previous year when they specifically hoped for something (after having been asked to explain 197 and provide examples of differences between wanting or desiring something, and hoping for 198 something).

199 We acknowledge that our sample was not random; however, it was not the goal of this 200 study to determine hope norms for the Croatian population, nor have such studies on hope been 201 conducted anywhere in the world. Likewise, the most hoped-for things in life listed by the 202 students and workers of health professions should not be taken as representative, outside perhaps 203 health professions, as hopes and life goals depend on a multitude of factors, including those 204 intrinsic, generational, social and cultural (Grouzet et al. 2005; Twenge et al. 2012).

205 The positive association we found between a person's trait hope and their levels of hope 206 for different specific events, coupled with the weak to moderate strength of those correlations 207 ( $\mathrm{r}=0.18$ to 0.48$)$ and the differences in which individuals ranked 4 factors compromising trait 
208 hope (self-confidence, ambition, optimism, and social support) according to how much they

209 contributed to their levels (intensity) of hope for specific events (Kendall's W from 0.002 to

210 0.15), indicates that specific hopes of individuals are most likely mediated by factors that do not

211 compromise the IHS trait instrument. As determination and increased goal oriented actions are

212 invoked by the changes in the intensity of hope(ing) for that goal (Averill et al. 1990), and

213 multiple factors have been found to influence hoping on patients recovering from stroke or spinal

214 cord injuries (Soundy et al. 2014) further research should focus on determining the most

215 influential factors for specific hopes, especially ones associated with better health outcomes (Van

216 Allen et al. 2015). Additionally, effectiveness of interventions aimed at increasing specific or

217 generalized hoping should be assessed. 


\section{Acknowledgments}

219 We would like to thank all the students of the 2011/12 generation of health studies in Split, as 220 well as the attendees of the 2012 Education for lecturers of nursing courses in Split for their

221 participation in the study. We would also like to thank Linda Ivas, Ana Utrobičić, Adrijana

222 Banožić and Ana Jerončić for their input with questionnaire design and implementation, and to

223 Ana Marušić for her help in reviewing our manuscript. 
226

227

228

229

230

231

232

233

234

235

236

237

238

239

240

241

242

243

244

245

246

247

248

249

250

251

252

253

254

255

256

257

258

259

260

261

262

263

264

265

266

267

References:

Alberto J, and Joyner B. 2008. Hope, optimism, and self-care among Better Breathers Support Group members with chronic obstructive pulmonary disease. Applied Nursing Research 21:212-217. 10.1016/j.apnr.2006.12.005

Averill JR, Catlin G, and Chon KK. 1990. Rules of hope: Springer-Verlag.

Benedict XVI P. 2006. Compendium of the Catechism of the Catholic church. London: Catholic Truth Society.

Boyd K. 2015. Hope, Despair, and Other Strategies of Patients. In: Schramme T, and Edwards S, eds. Handbook of the Philosophy of Medicine: Springer Netherlands, 1-9.

Bright FA, Kayes NM, McCann CM, and McPherson KM. 2011. Understanding hope after stroke: a systematic review of the literature using concept analysis. Top Stroke Rehabil 18:490-508. 10.1310/tsr1805-490

Croatian bureau of statistics. 2013. Census of population, households and dwellings 2011, population by citizenship, ethnicity, religion and mother tongue. Statistical Reports. Zagreb, Croatia.

Cutcliffe JR, and Herth K. 2002. The concept of hope in nursing 1: its origins, background and nature. Br $J$ Nurs 11:832-840.

Erikson EH. 1964. Insight and responsibility. Lectures on the ethical implications of psychoanalytic insight. New York: W. W. Norton \& Co.

Evangelista LS, Doering LV, Dracup K, Vassilakis ME, and Kobashigawa J. 2003. Hope, mood states and quality of life in female heart transplant recipients. $J$ Heart Lung Transplant 22:681-686.

Grouzet FM, Kasser T, Ahuvia A, Dols JM, Kim Y, Lau S, Ryan RM, Saunders S, Schmuck P, and Sheldon KM. 2005. The structure of goal contents across 15 cultures. J Pers Soc Psychol 89:800-816. 10.1037/0022-3514.89.5.800

Kylma J, and Vehvilainen-Julkunen K. 1997. Hope in nursing research: a meta-analysis of the ontological and epistemological foundations of research on hope. $J$ Adv Nurs 25:364-371.

Lopez SJ, and Snyder CR. 2003. Positive psychological assessment : a handbook of models and measures. Washington, D.C.: American Psychological Association ; London : Eurospan.

Meadows LA, Kaslow NJ, Thompson MP, and Jurkovic GJ. 2005. Protective factors against suicide attempt risk among African American women experiencing intimate partner violence. Am J Community Psychol 36:109-121. 10.1007/s10464-005-6236-3

Schrank B, Stanghellini G, and Slade M. 2008. Hope in psychiatry: a review of the literature. Acta Psychiatr Scand 118:421-433. 10.1111/j.1600-0447.2008.01271.x

Schrank B, Woppmann A, Sibitz I, and Lauber C. 2011. Development and validation of an integrative scale to assess hope. Health Expect 14:417-428. 10.1111/j.13697625.2010.00645. $x$

Smith NH. 2012. From the Concept of Hope to the Principle of Hope. In: Horrigan J, and Wiltse E, eds. Hope against Hope: Philosophies, Cultures and Politics of Possibility and Doubt. Amsterdam, Netherlands: Rodpi 3-22.

Snyder CR, Sympson SC, Ybasco FC, Borders TF, Babyak MA, and Higgins RL. 1996. Development and validation of the State Hope Scale. J Pers Soc Psychol 70:321-335. 
Soundy A, Stubbs B, Freeman P, Coffee P, and Roskell C. 2014. Factors influencing patients' hope in stroke and spinal cord injury: A narrative review. International Journal of Therapy and Rehabilitation 21:210-218. 10.12968/ijtr.2014.21.5.210

Statistics Austria. 2001. Bevölkerung 2001 nach Religionsbekenntnis und Staatsangehörigkeit. Vienna.

Suris JC, Parera N, and Puig C. 1997. Gender differences in health perception and health care seeking among adolescents in barcelona. Int J Adolesc Med Health 9:1-8. 10.1515/IJAMH.1997.9.1.1

Titus 1:2. 2011. The Holy Bible: New International Version. London: Hodder \& Stoughton.

Twenge JM, Campbell WK, and Freeman EC. 2012. Generational differences in young adults' life goals, concern for others, and civic orientation, 1966-2009. J Pers Soc Psychol 102:1045-1062. 10.1037/a0027408

Van Allen J, Steele RG, Nelson MB, Peugh J, Egan A, Clements M, and Patton SR. 2015. A Longitudinal Examination of Hope and Optimism and Their Role in Type 1 Diabetes in Youths. J Pediatr Psychol. 10.1093/jpepsy/jsv113

White HGE. 1914. Hesiod, the Homeric Hymns, and Homerica, with an English translation [and an introduction] by Hugh G. Evelyn-White: 1914.

Zink Jadaa D-A. 2008. Resources that mitigate caregiver burden: Hope, coping, and social support. 2008. Dissertation Abstracts International: Section B: The Sciences and Engineering 69. 
290 Table 1. Integrative hope subscale scores and levels of hope designated on visual-analog 291 scales (VAS) for students $(n=161)$ and workers $(n=88)$ of health professions

\begin{tabular}{|l|c|c|c|}
\hline \multicolumn{1}{|c|}{ Variable } & $\begin{array}{c}\text { Students } \\
\text { Median (IQR) }\end{array}$ & $\begin{array}{c}\text { Workers } \\
\text { Median (IQR) }\end{array}$ & P* \\
\hline Integrative hope total score & $111.0(105-118)$ & $115.0(106-121)$ & 0.065 \\
\hline Integrative hope subscale & \multicolumn{3}{|l|}{} \\
\hline Trust and confidence & $32.5(31-36)$ & $36.0(32-38)$ & $<0.001$ \\
\hline Lack of perspective & $27.0(24-30)$ & $26.0(24-30)$ & 0.653 \\
\hline Positive future orientation & $27.0(25-29)$ & $27.0(25-29)$ & 0.873 \\
\hline Social relations and personal value & $24.0(22-26)$ & $26.5(23-28)$ & $<0.001$ \\
\hline Total hope score & & & \\
\hline Levels of hope on VAS for & & $/$ & $/$ \\
\hline Finishing studies in time & $90(80-100)$ & & $<0.001$ \\
\hline Being healthy at the age of 60 & $70(60-80)$ & $85(70-92)$ & 0.041 \\
\hline The most hoped-for thing in life & $90(76-100)$ & $95(80-100)$ & \\
\hline
\end{tabular}


293 Table 2. Correlation of trait hope, specific hopes and age of students $(n=161)$ and workers

$294 \quad(\mathbf{n}=\mathbf{8 8})$ of health professions

\begin{tabular}{|l|c|c|c|c|}
\hline \multicolumn{1}{|c|}{$\begin{array}{c}\text { Correlation } \\
\left(\boldsymbol{\rho}^{*}, \mathbf{9 5 \%} \mathbf{C I}\right)\end{array}$} & $\begin{array}{c}\text { Hope for } \\
\text { finishing } \\
\text { studies in time }\end{array}$ & $\begin{array}{c}\text { Hope for being } \\
\text { healthy at the } \\
\text { age of 60 }\end{array}$ & $\begin{array}{c}\text { Most hoped- } \\
\text { for thing in life }\end{array}$ & Age \\
\hline $\begin{array}{l}\text { Students' trait } \\
\text { hope }\end{array}$ & $\begin{array}{c}0.275 \\
(0.124 \text { to } 0.413)\end{array}$ & $\begin{array}{c}0.182 \\
(0.027 \text { to } 0.328)\end{array}$ & $\begin{array}{c}0.318 \\
(0.169 \text { to } 0.452)\end{array}$ & $\begin{array}{c}0.0261 \\
(-0,130 \text { to } 0,181)\end{array}$ \\
\hline $\begin{array}{l}\text { Workers' trait } \\
\text { hope }\end{array}$ & $/$ & 0.421 & 0.486 & -0.0140 \\
$(0.210$ to 0.595$)$ & $(0.278$ to 0.650) & $(-0.340$ to 0.0732$)$ \\
\hline
\end{tabular}

$295 *$ Spearman's rank correlation coefficient 
296 Table 3. Concepts that students $(n=157)$ and workers $(n=78)$ listed as their answers to the 297 question: "What do you most hope for in life?"

\begin{tabular}{|l|c|c|c|}
\hline \multirow{2}{*}{ Answer } & \multicolumn{2}{|c|}{ No (\%) of } & \multirow{2}{*}{$\boldsymbol{P}^{*}$} \\
\cline { 2 - 3 } & students & workers & $<0.001$ \\
\hline Health & $73(46.50)$ & $55(70.51)$ & 0.7237 \\
\hline Happiness & $39(24.84)$ & $17(21.79)$ & 0.0181 \\
\hline Work/Carrier & $38(24.20)$ & $8(10.26)$ & 0.0465 \\
\hline Lamily & $29(18.47)$ & $6(7.69)$ & 0.0865 \\
\hline To finish studies & $10(6.37)$ & $11(14.10)$ & 0.0726 \\
\hline To achieve my goals & $9(5.73)$ & $/$ & 0.3775 \\
\hline Money & $7(4.46)$ & $1(1.28)$ & 0.7251 \\
\hline Children & $6(3.82)$ & $3(5.13)$ & 0.6660 \\
\hline Marriage & $4(2.55)$ & $2(2.56)$ & 0.3754 \\
\hline Living & $4(2.55)$ & $/$ & 0.8856 \\
\hline Winning a lottery & $4(2.55)$ & $3(3.85)$ & 0.8049 \\
\hline Peace & $2(1.27)$ & $/$ & 0.1852 \\
\hline To be content & $2(1.27)$ & $4(5.13)$ & 0.0276 \\
\hline $\begin{array}{l}\text { Advanced } \\
\text { age/longevity }\end{array}$ & $1(0.64)$ & $5(6.41)$ & 0.0773 \\
\hline Spiritual fulfillness & $1(0.64)$ & $4(5.13)$ & 0.0773 \\
\hline Children's happiness & $1(0.64)$ & $4(5.13)$ & 0.2073 \\
\hline Mingling & $/$ & $2(2.56)$ & 0.2073 \\
\hline Other $\dagger$ & $1(0.64)$ & $2(2.56)$ & 0.8049 \\
\hline
\end{tabular}

*Chi-square test

$299+$ Includes concepts: to remain the same, to have no worries, everything, helping family

300 members, good grades, good relationship with colleagues, fun, food, knowledge, social security, 301 grandchildren, for no tragedies in life. 